\title{
The effect of soy and soy product supplementation on circulating adiponectin and leptin concentration: A systematic review and meta-analysis of randomized controlled trials
}

\author{
Amirhossein farokhzad ${ }^{1}$ and Wolfgong Marx ${ }^{2}$ \\ ${ }^{1}$ Affiliation not available \\ ${ }^{2}$ Sichuan University
}

September 11, 2020

\begin{abstract}
Background: Adiponectin is a well-known adipokines with anti-inflammatory effects. Leptin is known as its effect on food intake and energy. Here in present study we aimed to evaluate possible effect of soy supplementation on circulating adiponectin and leptin. Methods: Systematic search performed up to April 2020 in the following databases: PubMed, Scopus and Cochrane. All RCTs which evaluated the effect soy supplementation on adiponectin and leptin concentration were included. Results: According to our analysis on 14 studies, in overall, soy supplementation had significant effect on adiponectin concentration. Furthermore, soy supplementation has no significant effect on serum leptin concentration, but subgroup analysis showed significant increase in leptin concentration in studies with doses more than $20 \mathrm{~g} /$ day of soy supplementation. Conclusion: Soy supplementation has significant increasing effect on adiponectin level. Whilst pooled effect size did not show any significant effect of soy product supplementation on leptin level.
\end{abstract}

\section{What is already known about this topic?}

* Some previous studies have shown the beneficial effects of soy supplementation.

* There has been no meta-analyses to summarize the effect of soy supplementation on circulating adiponectin and leptin in adults.

\section{What does this article add?}

* This study is the first systematic review and meta-analysis that has been designed to evaluate the effect of soy supplementation on circulating adiponectin and leptin in adults.

* The present study suggests that soy supplementation has significant increasing effect on adiponectin level.

* However, pooled effect size did not show any significant effect of soy product supplementation on leptin level.

\section{Introduction}

Adiponectin is the most abundant circulating adipokine secreted from adipose tissue in the blood. The fundamental role of adiponectin in fatty acid oxidation and glucose homeostasis, suppressing fat accumulation and promoting antioxidation reported in previous studies ${ }^{1-3}$. Lower adiponectin level reported in type 2 diabetes, metabolic syndrome, and cardiovascular disease $(\mathrm{CVD})^{4}$; therfore in these patients lower adiponectin level has the etiological importance of forming insulin resistance ${ }^{5}$. Higher adiponectin concentration associated with lower risk of $\mathrm{CVDs}^{6}$. Leptin, other well-known adipokine also reported to be involved in glucose uptake 
and glycolysis exactly effect on glycolytic enzymes; it's role in production of inflammatory cytokines also has been reported ${ }^{7,8}$. Leptin mostly known as a hormone which regulate food intake and energy expenditure ${ }^{9}$.

Soy is a valuable plant protein source; its use is common in several parts of the world particularly southeastern parts of asia ${ }^{10}$. Soy and soy products because of its isoflavones known as one of the rich sources of micronutrients, phytochemicals and powerful antioxidants. Biologically active heterocyclic phenols of soy after ingestion could act sevral function in body ${ }^{11}$. Genistein and daidzein, the main isoflavones of soy implicated in preventing metabolic diseases such as cancer, osteoporosis, infertility, diabetes and CVDs ${ }^{12}$. These isoflavomnes are potent anti-inflammatory agents; Equol, the metabolite of diadzein following function of gut microbiome, reported to possess antioxidant effects and also it has a tendency for binding to estrogen receptors ${ }^{13}$. Apart from different varient of soy and their possible different effect, some polymorphisms alter the individual's response to isoflavones, worsening inflammatory status and causing mutations, but in some polymorphisms, soy intake decreases tumor growth by reducing inflammation ${ }^{14}$.

However, some experimental studies have reported beneficial anti-inflammatory effects of soya protein or isoflavone, shown by increasing adiponectin ${ }^{15-17}$. Previous studies reported inconsistent results regarding effect of soy and soy products on adiponectin and leptin level; several studies showed no statistically significant change in the adiponectin ${ }^{18-26}$. Of interest, Llanos et al. ${ }^{27}$ reported soy protein supplement (40 g) resulted in significant adiponectin reduction. Furthermore, there was a trend toward decreased circulating adiponectin with the soy supplement compared to placebo in Maskarinec et al. study ${ }^{20}$, consistent with the report by Llanos et al. ${ }^{27}$. Most studies did not report any change in leptin as well; except but in two studies, ${ }^{26,27}$ intervention of soy protein supplement resulted in lower leptin reduction compared with control group. Due to lack of comprehensive systematic review and meta-analysis on one hand, and inconsistent results on the other hand, we aimed to systematically review the effect of soy and soy products on circulating adiponectin and leptin. Findings of present study enlighten our knowledge in this context for recommendation.

\section{Methods}

\section{Search Strategy}

The systematic review and meta-analysis was reported based on the guidelines of Preferred Reporting Items for Systematic Reviews and Meta-Analyses (PRISMA) ${ }^{28}$. A computerized literature search was performed from inception to April 2020 using various databases including PubMed (http://www.pubmed.com), ISI Web of Science (http://www.webofknowledge.com), Scopus (http://www.scopus.com), and Google Scholar (http://www.scholar.google.com) search. The following phrases and their combinations of MeSH and nonMeSH terms were used, including: "soy protein", "soybean proteins", "soy isoflavones", "soy", "isoflavones", "soy diet replacement", "meal replacement therapy", "adipokines" "adiponectin", "leptin", "controlled trial", "randomized", "randomised", "random", "randomly", "randomized clinical trial", "RCT", "blinded", "double blind", "double blinded", "trial", "controlled clinical trial", "crossover procedure", "cross-over trial", "double blind procedure "and "equivalence trial". Reference lists of all articles were examined for identification of further eligible studies.

\section{Eligibility Criteria}

Studies were selected by applying the following Population-Intervention-Comparator-Outcomes-Study design (PICOS) criteria $^{28}: 1$ ) subjects received oral soy and soy products supplementation, as a nutritional strategy; 2) original randomized-controlled trial researches and 3) reporting at least one outcome measure of adipokines (adiponectin and leptin) ; 4) presented data of interest as mean and standard deviation (SD) of adiponectin and leptin in both intervention and placebo groups; and 5) had a trial duration of more than 4 weeks. Exclusion criteria were: 1) using a mixture of soy protein or isoflavones extract only in intervention group, not including a placebo group; 2) semi experimental, nonrandomized trials and trials without control groups; 3) duplicate studies with the same population (several papers reported the same data); 4) enrolled pregnant or lactating women; 5) experimental and animal studies; and 6) reviews, letters to editor, editorial articles, or case reports. 


\section{Selection strategy}

After a primary search, all recorded articles found from electronic or manual searches were entered into endnote software for screening (EndNote X6, Thomson Reuters, New York). Titles and received abstracts of papers were screened by the search strategy. studies were evaluated independently by two reviewers and selected according to the inclusion criteria independently. Articles including eligibility criteria in the title/abstract screening were selected to be checked by full-text. All clinical trials were included in the present met analysis if our inclusion criteria met. All categorized trials were retrieved by either of the authors. On the basis of the information within the full information, we used a standardized form to select the trials eligible for inclusion in the review. Contradictions between the authors were solved by consensus or third researcher.

\section{Data extraction}

We extracted following required data using a pre-designed standardized electronic form (Excel, Microsoft Office): first author's name, publication year and country, research design, age and gender of subjects, sample size, duration of intervention and soy dose. Also, we extracted mean and standard deviation (SD) of plasma adipokines status (adiponectin and leptin) at baseline and after the intervention. Any reported standard errors of mean (SEM), were converted to SDs through following formula by SD $=\mathrm{SEM} \times[?] \mathrm{n}(\mathrm{n}$ is the number of participants in each group). Finally, in studies which reported data in graphical figures, data extraction was performed by using GetData Graph Digitizer 2.24 29 .

\section{Study quality}

The Cochrane Collaboration tool was used for assessing the risk of bias, since it has been accepted that trial inclusion with a high risk of bias may distort the results of a meta-analysis ${ }^{30,31}$. The quality of all included studies were evaluated by based on the following factors: randomization sequence generation; allocation concealment; blinding of participants, personnel, investigator, and assessor; attrition rates; and financial interest by companies. These were given a rating of low, unclear, or high risk of bias. A randomized controlled trial (RCT) was ranked as having low, medium, or high-risk overall based on the key areas of allocation concealment, reporting of attrition rates, and participants and assessor (high $=$ all 4 factors rated high, medium $=2$ or 3 factors rated high or unclear, and low = all key areas rated low).

Analyses and measures of treatment effect

Mean changes and SD were computed for continuous variables for every study to calculate effect size. As for studies with no reported SD of the mean difference, following formula were used: SD change = square root $\left[\left(\mathrm{SD}_{\text {baseline }}{ }^{2}+\mathrm{SD} \text { final }{ }^{2}\right)-(2 \times 0.8 \times \text { SD baseline } \mathrm{x} \text { SD final })\right]^{32}$. Standardized mean changes were used for variables pooled on the different scales. Between-study heterogeneity was assessed using the chi-squared $\left(\chi^{2}\right)$ test and quantified using the $\mathrm{I}^{2}$ statistic, which represents the percentage of the total variation across studies that is attributable to heterogeneity rather than to chance. Significant heterogeneity was defined with a $\mathrm{P}$-value of $<0.05$.

The random effects model was applied to compute the weighted mean differences (WMDs) with $95 \%$ confidence intervals (CIs) for estimating the overall effect. To evaluate whether the results could have been affected distinctly by a single study, an influence or sensitivity analysis was carried out ${ }^{33}$. Subgroup analysis was also performed, based on the gender of participant (male, female or both), baseline BMI (over $30 \mathrm{~kg} / \mathrm{m}^{2}$ and $30 \mathrm{~kg} / \mathrm{m}^{2}$ or lower), dose of soy protein (over $20 \mathrm{~g} /$ day and $20 \mathrm{~g} /$ day or lower), duration of studies (over 12 weeks and 12 weeks or lower), supplementation type (soy-based meal replacement, soy powder or capsule supplement) and study design (randomized cross over or parallel). Publication bias was assessed by Begg's rank correlation test and Egger's regression asymmetry test. Funnel plots also depicted the effect sizes (differences in means) against their corresponding standard errors. Statistical analyses were performed using STATA 11.2 software (StataCorp, College Station, Texas, USA).

\section{Results}


Search results and overview of included studies

Our search led to 462 relevant studies. After duplicates removing, a wide range of screening of the titles and abstracts, the careful assessment was performed on 454 related articles. Of these, 23 articles remained after considering the inclusion and exclusion criteria for the eligibility. Eventually, 18 articles, including, 14 effect sizes for adiponectin and 14 effect sizes for leptin, which studied a total of 1042 and 1073 participants respectively and aged 28.9 - 69 years, were identified in the current systematic review and meta-analysis. One study ${ }^{34}$ just reported baseline data in the article paper and we did not receive raw data for after trial data from the authors. This listed number is inclusive of people who were dropouts in some studies. Figure $\mathbf{1}$ represents the selection process and reasons for excluding the studies. The data inTable $\mathbf{1}$ illustrates the main characteristics of the articles in our systematic review and meta-analysis.

In brief, the studies were published between 2009 and 2019. The duration of these RCTs ranged between 4 weeks to 24 months. The total number of participants who completed the studies in inclusion criteria was 511 participants in the intervention and 531 in the placebo groups for adiponectin and 544 participants in the intervention and 529 in the placebo groups for leptin. Soy protein have been used in a variety of forms in these studies like soy-based meal replacement ${ }^{18-20,25,26,35,36}$, soy powder or formula ${ }^{15-17,21,22,24,27,37}$ and capsule supplement ${ }^{19,23,38}$. However most of studies have been used soy powder or formula. The dose of soy protein supplementation was 6 to $50 \mathrm{~g} /$ day among these studies.

Three studies used a randomized crossover design ${ }^{18,24,27}$, two of them was also single blind ${ }^{18,27}$ and the other study had the design of double-blind ${ }^{24}$. Among 18 studies 9 studies were conducted in $\mathrm{n}$ the United States $^{15,18-21,24,25,27,36}$. The effect of soy protein on both adiponectin and leptin concentration was examined in 10 studies; and 4 studies only reported adiponectin ${ }^{17,18,25,38}$ and 4 studies only reported leptin ${ }^{35-37,39}$. Overall, 18 effect sizes were extracted from these studies for adiponectin and leptin concentration.

Results from quality assessments

The quality details of bias assessment are presented in Table 2, and the Cochrane Collaboration tool was applied for evaluating the risk of bias ${ }^{32}$. Briefly, participant's random allocation was mentioned in all included trials. However, eight trials described the method of random sequence generation ${ }^{15-17,21-24,26}$. Five trials reported allocation concealment ${ }^{15,17,22,25,37}$. Most studies represented low risk of bias based on selective reporting; nevertheless, 5 studies had high risk of bias ${ }^{17,18,23,24,35}$. All studies had a low risk of bias for incomplete outcome data. Five studies had a low risk of bias for blinding of participants and personnel ${ }^{15,18,21,22,25}$ and six studies had high risk of bias regarding blinding outcome assessors ${ }^{15,16,22,26,37,39}$. All of studies had low or unclear risk of bias regarding other potential threats to validity.

Findings from the meta-analysis

Effects of soy protein supplementation on serum adiponectin concentration

According to our analysis on 14 studies, in overall, soy and soy product consumption had significant effect on adiponectin concentration: $\mathrm{WMD}=0.09 ; 95 \% \mathrm{CI}: 0.04,0.15 ; \mathrm{P}=0.001$. There was significant heterogeneity among the studies (Cochran's Q test $=165.27, \mathrm{P}=0.000, \mathrm{I}^{2}=92.7 \%$ ). Subgroup analysis of gender of participant, baseline BMI, dose of soy protein, duration of studies, supplementation type and study design had no significant effect on adiponectin concentration in any subgroups. The results of subgroup analysis are shown in Table $\mathbf{3}$ and the forest plot is shown inFigure $\mathbf{2}$.

Effects of soy protein supplementation on leptin concentration

As outlined in Figure 2 , our preliminary analysis indicated that soy and soy products consumption have no significant difference in serum leptin concentration (WMD $=0.12 ; 95 \% \mathrm{CI}$ : $-3.26,3.51 ; \mathrm{P}=0.921$ ) Also, significant heterogeneity was observed among studies (Cochran's Q test $=109.59, \mathrm{P}=0.000, \mathrm{I}^{2}=88.1 \%$ ). Subgroup analysis was conducted to check if the effect of soy protein supplementation on serum leptin is different according to gender of participant, baseline BMI, dose of soy protein, duration of studies, supplementation type and study design (Table 3 ). This analysis revealed that the pooled effect of soy protein 
supplementation on leptin concentration was influenced by dose of soy protein ([?]20 g/day versus $>20 \mathrm{~g} /$ day), in this way that, a significant increase in leptin concentration was found in studies that used more than 20 $\mathrm{g}$ /day soy protein $(\mathrm{WMD}=4.405 ; 95 \% \mathrm{CI}: 0.578,8.232 ; \mathrm{P}=0.024)$. Subgroup analysis didn't show any significant effect of soy protein supplementation on leptin concentration in other subgroups.

Sensitivity analysis and publication bias

Sensitivity analysis indicated that the removal of any of the studies from the meta-analysis, create no change in the results of the meta-analysis on leptin concentration whereas, the results on adiponectin concentration were sensitive to omitting 1 study $^{18}$. Funnel plots for adiponectin and leptin were visually symmetrical (Figure 4 and 5), and the results of Begg's test did not determine any evidence of publication bias in studies that examine the effect of soy protein consumption on adiponectin (Begg's test, $\mathrm{P}=0.059$ ) and on leptin (Begg's test, $\mathrm{P}=0.861$ ).

\section{Discussion}

To our knowledge, the efficacy of soy protein and soy products has not been distinctly established for adipocytokines concentration; therefore, this systematic review and meta-analysis provided insight into the potential advantages conferred by such supplementation to allow healthy and unhealthy people to make informed decisions on their usage. This meta analysis suggests that soy protein supplementation have a meaningful effect on plasma levels of adiponectin; however, pooled effect size were not significant for leptin concentration.

The soy protein beneficial effects on traditional CVD risk factors, blood pressure and primarily lipids, has been demonstrated previously ${ }^{40,41}$. The evidence for a dietary protein intake association on novel CVD risk factors is less conclusive. A high adiponectin concentration is related to insulin sensitivity and decreased risk for CVDs. Adiponectin is also an independent marker of risk for metabolic syndrome in patients with type 2 diabetes ${ }^{42}$. Generally, serum adiponectin concentration are decreased in diabetes type- 2 and obesity and this is considered to be of etiological importance in causing insulin resistance ${ }^{5}$. Therefore, any measure that increases adiponectin concentration would be predicted to improve insulin resistance. Contrary to adiponectin, reduced plasma leptin levels are positively correlated with parameters of overall obesity and CVDs $^{43}$. Leptin is secreted exclusively by adipocytes, and this secretion is regulated by the size of fat stores both in pathophysiological and in physiological states ${ }^{44}$. This protein provides the brain with information about the body's fat deposits. This acts as a feedback mechanism that can function as a lipostat ${ }^{45}$ via control of satiety, energy expenditure, and other neuroendocrine functions ${ }^{46}$. Because of all of these pathological conditions, it is important to design strategies to reduce leptin levels.

Despite the heterogeneity of the data, our meta analysis showed that serum adiponectin concentration increased in participant taking isoflavones compared to placebo. However, performed subgroup analysis based on sex, baseline BMI, dose, duration, type of supplementation and study design were did not showed any significant effect of soy and soy product supplementation on adiponectin serum level. We found that soy protein supplementation resulted in no significant reduction in leptin concentration, but we observed a significant increase in leptin concentration in studies that used more than $20 \mathrm{~g} /$ day soy protein compared with control group. The observed increase in plasma leptin was not documented in any of studies, but in two studies ${ }^{26,27}$ intervention of soy protein supplement resulted in lower leptin reduction compared with control group. Deibert et al. ${ }^{26}$ have used lifestyle change group as control group that attended 6 weekly teaching sessions about nutrition and physical exercise. Also, Llanos et al, ${ }^{27}$ have designed interventions included 10 weeks of consumption of a tomato-based diet and 10 weeks of consumption of a soy-based diet. Although these two studies have used more than $20 \mathrm{~g}$ /day soy protein, but may distorted the results, because control group of these studies resulted more reduction of leptin concentration compared with soy-based diet. As well as, studies that used less than $20 \mathrm{~g}$ /day soy protein had a trend toward decreased circulating leptin with the soy supplement compared to placebo $(\mathrm{p}=0.056)$. Due to standard method and strategy of supplementation in these studies, this result is more reliable.

To our knowledge, interactions between adiponectin and estrogens have not yet been fully characterized. 
Higher concentrations of adiponectin in women than in men of comparable BMI and age suggest that estrogens might have a stimulatory effect on adipocytes production adiponectin ${ }^{47,48}$. The use of soy products clearly appears to be beneficial from a viewpoint of cardiovascular disease, leastways in part, because of the actions of isoflavones which resemble estrogen effect ${ }^{49}$. Because of these effects, 7 studies that included in this meta analysis conducted trial on postmenopausal women and hypothesized that adipocytokines concentration in postmenopausal women using soy protein could be higher than in women without soy protein using $15,16,20,25,27,36,37$. Wide array of both in vivo and in vitro studies done by investigators showing an effect of estrogens on adipocyte for adipocytokines production. They concluded that adiponectin concentrations in postmenopausal women using estrogens could be higher than in women without hormone replacement therapy $^{50,51}$. Also, Casabiell et al. found what appeared to be a direct estradiol effect to stimulate leptin production in a tissue organ culture ${ }^{52}$. In fact, isoflavones of soy are relatively potent agonists of the $\beta$-of estrogen receptor isoform, and its effects on adipocyte function and differentiation have been reported ${ }^{53}$, and we conclude soy protein effects on adipocytokines is due to estrogen-like probable actions of isoflavones.

Many studies have showed that soy isoflavones have multiple biological functions and may help to restore adiponectin expression. Soy isoflavones (Both genistein and daidzein) significantly inhibited the TNF-a mediated downregulation of adiponectin expression in adipocytes. Some possible molecular mechanisms are that these active components (I) inhibit the TNF- a mediated JNK signaling pathway involved in adiponectin expression, or (II) inhibit the TNF- a mediated downregulation of FoxO1, which is involved in adiponectin expression, (III) function as PPAR $\gamma$ agonists and increase the transcriptional activity of PPAR $\gamma$, which ultimately leads to the inhibition of the TNF- a mediated downregulation of adiponectin expression ${ }^{54}$. Also, high dosage of soy isoflavones may enhance circulating leptin level in insulin resistant rats by elevating the efficiency of translating leptin mRNA into leptin protein ${ }^{55}$.

The strengths of our study is that we considered all published clinical trials conducted on the effect of soy protein supplementation on adipocytokines. In addition, we considered all RCTs which were done on individuals with different health conditions. Also different study designs and the lack of controlling for baseline measures in some studies should be taken into account. Moreover, many factors can affect the high heterogeneity and the inconclusive findings stated different manufacturers of soy protein and variations in soy protein classifications between countries may contribute to the inconsistencies in results.

\section{Conclusion}

Soy protein supplementation, had a beneficial effect on adiponectin. Additional well-designed RCTs recruiting a homogenous group of participants are required to further examine this subject. In addition, the effects of soy protein on other adipocytokines, for example chemerin, visfatin and omentin, metabolic parameters, and the cost-effectiveness of this supplement, should be clarified in further studies.

\section{Conflict of interest}

The authors declare no conflict of interest.

\section{Acknowledgments}

None.

\section{Funding source}

This research did not receive any specific grant from funding agencies in the public, commercial, or not-forprofit sectors.

\section{References}

1. Stern JH, Rutkowski JM, Scherer PE. Adiponectin, leptin, and fatty acids in the maintenance of metabolic homeostasis through adipose tissue crosstalk. Cell metabolism.2016;23(5):770-784.

2. Abou-Samra M, Selvais CM, Dubuisson N, Brichard SM. Adiponectin and Its Mimics on Skeletal Muscle: 
Insulin Sensitizers, Fat Burners, Exercise Mimickers, Muscling Pills... or Everything Together? International Journal of Molecular Sciences.2020;21(7):2620.

3. Achari AE, Jain SK. Adiponectin, a therapeutic target for obesity, diabetes, and endothelial dysfunction.International journal of molecular sciences. 2017;18(6):1321.

4. Ferrarezi DA, Cheurfa N, Reis AF, Fumeron F, Velho G. Adiponectin gene and cardiovascular risk in type 2 diabetic patients: a review of evidences. Arquivos Brasileiros de Endocrinologia ES Metabologia. 2007;51(2):153-159.

5. Travier N, Buckland G, Vendrell JJ, et al. Changes in metabolic risk, insulin resistance, leptin and adiponectin following a lifestyle intervention in overweight and obese breast cancer survivors. European journal of cancer care.2018;27(4):e12861.

6. Laughlin GA, Barrett-Connor E, May S, Langenberg C. Association of adiponectin with coronary heart disease and mortality: the Rancho Bernardo study. American journal of epidemiology. 2006;165(2):164-174.

7. La Cava A. Leptin in inflammation and autoimmunity. Cytokine. 2017;98:51-58.

8. Denroche HC, Huynh FK, Kieffer TJ. The role of leptin in glucose homeostasis. Journal of diabetes investigation. 2012;3(2):115-129.

9. Ahima RS. Revisiting leptin's role in obesity and weight loss. The Journal of clinical investigation. 2008;118(7):2380-2383.

10. Jheng HF, Hirotsuka M, Goto T, Shibata M, Matsumura Y, Kawada T. Dietary low-fat soy milk powder retards diabetic nephropathy progression via inhibition of renal fibrosis and renal inflammation. Molecular nutrition \& food research. 2017;61(3):1600461.

11. González-Montoya M, Hernández-Ledesma B, Silván JM, Mora-Escobedo R, Martínez-Villaluenga C. Peptides derived from in vitro gastrointestinal digestion of germinated soybean proteins inhibit human colon cancer cells proliferation and inflammation. Food chemistry. 2018;242:75-82.

12. Peng Y, Shi Y, Zhang H, Mine Y, Tsao R. Anti-inflammatory and anti-oxidative activities of daidzein and its sulfonic acid ester derivatives. Journal of Functional Foods.2017;35:635-640.

13. Meng H, Fu G, Shen J, et al. Ameliorative effect of daidzein on cisplatin-induced nephrotoxicity in mice via modulation of inflammation, oxidative stress, and cell death. Oxidative medicine and cellular longevity. $2017 ; 2017$.

14. Holmdahl R, Sareila O, Olsson LM, Bäckdahl L, Wing K. Ncf1 polymorphism reveals oxidative regulation of autoimmune chronic inflammation. Immunological reviews.2016;269(1):228-247.

15. Charles C, Yuskavage J, Carlson O, et al. Effects of high-dose isoflavones on metabolic and inflammatory markers in healthy postmenopausal women. Menopause (New York, NY). 2009;16(2):395.

16. Llaneza P, González C, Fernandez-Iñarrea J, et al. Soy isoflavones, diet and physical exercise modify serum cytokines in healthy obese postmenopausal women.Phytomedicine. 2011;18(4):245-250.

17. Ma L, Grann K, Li M, Jiang Z. A pilot study to evaluate the effect of soy isolate protein on the serum lipid profile and other potential cardiovascular risk markers in moderately hypercholesterolemic Chinese adults. Ecology of food and nutrition. 2011;50(6):473-485.

18. Zemel MB, Sun X, Sobhani T, Wilson B. Effects of dairy compared with soy on oxidative and inflammatory stress in overweight and obese subjects. The American journal of clinical nutrition. 2010;91(1):16-22.

19. Vargas ML, Almario RU, Buchan W, Kim K, Karakas SE. Metabolic and endocrine effects of longchain versus essential omega-3 polyunsaturated fatty acids in polycystic ovary syndrome. Metabolism. 2011;60(12):1711-1718. 
20. Maskarinec G, Steude JS, Franke AA, Cooney RV. Inflammatory markers in a 2-year soy intervention among premenopausal women. Journal of Inflammation. 2009;6(1):9.

21. Napora JK, Short RG, Muller DC, et al. High-dose isoflavones do not improve metabolic and inflammatory parameters in androgen-deprived men with prostate cancer. Journal of andrology. 2011;32(1):40-48.

22. Takahira M, Noda K, Fukushima M, et al. Randomized, double-blind, controlled, comparative trial of formula food containing soy protein vs. milk protein in visceral fat obesity. Circulation Journal. 2011;75(9):2235-2243.

23. Riesco E, Choquette S, Audet M, Lebon J, Tessier D, Dionne IJ. Effect of exercise training combined with phytoestrogens on adipokines and C-reactive protein in postmenopausal women: a randomized trial. Metabolism. 2012;61(2):273-280.

24. Rebholz C, Reynolds K, Wofford M, et al. Effect of soybean protein on novel cardiovascular disease risk factors: a randomized controlled trial. European journal of clinical nutrition. 2013;67(1):58-63.

25. Nadadur M, Stanczyk FZ, Tseng C-C, Kim L, Wu AH. The effect of reduced dietary fat and soy supplementation on circulating adipocytokines in postmenopausal women: a randomized controlled 2-month trial. Nutrition and cancer.2016;68(4):554-559.

26. Deibert P, Lazaro A, Schaffner D, et al. Comprehensive lifestyle intervention vs soy protein-based meal regimen in non-alcoholic steatohepatitis. World Journal of Gastroenterology. 2019;25(9):1116.

27. Llanos AA, Peng J, Pennell ML, et al. Effects of tomato and soy on serum adipokine concentrations in postmenopausal women at increased breast cancer risk: a cross-over dietary intervention trial. The Journal of Clinical Endocrinology 83 Metabolism. 2014;99(2):625-632.

28. Liberati A, Altman DG, Tetzlaff J, et al. The PRISMA statement for reporting systematic reviews and meta-analyses of studies that evaluate health care interventions: explanation and elaboration. Annals of internal medicine.2009;151(4):W-65-W-94.

29. Fedorov S. GetData Graph Digitizer version 2.24. Available at www getdata-graph-digitizer com. 2002;541:542.

30. Higgins JP, Altman DG, Gotzsche PC, et al. The Cochrane Collaboration's tool for assessing risk of bias in randomised trials. Bmj. 2011;343:d5928.

31. Liberati A, Altman DG, Tetzlaff J, et al. The PRISMA statement for reporting systematic reviews and meta-analyses of studies that evaluate health care interventions: explanation and elaboration. PLoS medicine. 2009;6(7):e1000100.

32. Borenstein M, Hedges LV, Higgins JP, Rothstein HR. Introduction to meta-analysis. John Wiley \& Sons; 2011.

33. Tobias A. Assessing the influence of a single study in the meta-anyalysis estimate. Stata Technical Bulletin. 1999;8(47).

34. Christie DR, Grant J, Darnell BE, Chapman VR, Gastaldelli A, Sites CK. Metabolic effects of soy supplementation in postmenopausal Caucasian and African American women: a randomized, placebo-controlled trial. American journal of obstetrics and gynecology. 2010;203(2):153. e151-153. e159.

35. Konig D, Deibert P, Frey I, Landmann U, Berg A. Effect of meal replacement on metabolic risk factors in overweight and obese subjects. Annals of Nutrition and Metabolism. 2008;52(1):74-78.

36. Wu AH, Stanczyk FZ, Martinez C, et al. A controlled 2-mo dietary fat reduction and soy food supplementation study in postmenopausal women. The American journal of clinical nutrition. 2005;81(5):1133-1141. 
37. Llaneza P, Gonzalez C, Fernandez-Inarrea J, Alonso A, Diaz F, Perez-Lopez FR. Soy isoflavones improve insulin sensitivity without changing serum leptin among postmenopausal women. Climacteric. 2012;15(6):611-620.

38. Lozovoy MAB, Bahls LD, Morimoto HK, Matsuo T, Dichi I. Blood pressure decrease with ingestion of a soya product (kinako) or fish oil in women with the metabolic syndrome: role of adiponectin and nitric oxide. British journal of nutrition.2012;108(8):1435-1442.

39. Deibert P, Solleder F, Konig D, et al. Soy protein based supplementation supports metabolic effects of resistance training in previously untrained middle aged males. The Aging Male. 2011;14(4):273-279.

40. Rebholz CM, Friedman EE, Powers LJ, Arroyave WD, He J, Kelly TN. Dietary protein intake and blood pressure: a meta-analysis of randomized controlled trials.American journal of epidemiology. 2012;176(suppl_7):S27-S43.

41. Reynolds K, Chin A, Lees KA, Nguyen A, Bujnowski D, He J. A meta-analysis of the effect of soy protein supplementation on serum lipids. The American journal of cardiology. 2006;98(5):633-640.

42. Yun JE, Sull JW, Lee HY, et al. Serum adiponectin as a useful marker for metabolic syndrome in type 2 diabetic patients. Diabetes/metabolism research and reviews.2009;25(3):259-265.

43. Imerbtham T, Thitiwuthikiat P, Jongjitwimol J, Nuamchit T, Yingchoncharoen T, Siriwittayawan D. Leptin Levels are Associated with Subclinical Cardiac Dysfunction in Obese Adolescents. Diabetes, Metabolic Syndrome and Obesity: Targets and Therapy. 2020;13:925.

44. Ahima RS, Flier JS. Adipose tissue as an endocrine organ. Trends in Endocrinology 83 Metabolism. 2000;11(8):327-332.

45. Triantafyllou GA, Paschou SA, Mantzoros CS. Leptin and hormones: energy homeostasis.Endocrinology and Metabolism Clinics. 2016;45(3):633-645.

46. Perez-Suarez I, Ponce-Gonzalez JG, de La Calle-Herrero J, et al. Severe energy deficit upregulates leptin receptors, leptin signaling, and PTP1B in human skeletal muscle.Journal of Applied Physiology. 2017;123(5):1276-1287.

47. Cnop M, Havel PJ, Utzschneider K, et al. Relationship of adiponectin to body fat distribution, insulin sensitivity and plasma lipoproteins: evidence for independent roles of age and sex. Diabetologia. 2003;46(4):459-469.

48. Nishizawa H, Shimomura I, Kishida K, et al. Androgens decrease plasma adiponectin, an insulinsensitizing adipocyte-derived protein. Diabetes. 2002;51(9):2734-2741.

49. Haun CT, Mobley CB, Vann CG, et al. Soy protein supplementation is not androgenic or estrogenic in college-aged men when combined with resistance exercise training.Scientific reports. 2018;8(1):1-13.

50. Gavrila A, Chan JL, Yiannakouris N, et al. Serum adiponectin levels are inversely associated with overall and central fat distribution but are not directly regulated by acute fasting or leptin administration in humans: cross-sectional and interventional studies. The Journal of Clinical Endocrinology $\&$ Metabolism. $2003 ; 88(10): 4823-4831$.

51. Sieminska L, Wojciechowska C, Niedziolka D, et al. Effect of postmenopause and hormone replacement therapy on serum adiponectin levels. Metabolism.2005;54(12):1610-1614.

52. Casabiell X, Pineiro V, Peino R, et al. Gender differences in both spontaneous and stimulated leptin secretion by human omental adipose tissue in vitro: dexamethasone and estradiol stimulate leptin release in women, but not in men. The Journal of clinical endocrinology and metabolism. 1998;83(6):2149-2155.

53. Zhang R, Liao E, Wu X, et al. Concentration of serum leptin and age in Chinese women and comparison with other races. Zhong nan da xue xue bao Yi xue ban= Journal of Central South University Medical 
sciences. 2009;34(11):1136-1141.

54. Yanagisawa M, Sugiya M, Iijima H, Nakagome I, Hirono S, Tsuda T. Genistein and daidzein, typical soy isoflavones, inhibit TNF- $\alpha$-mediated downregulation of adiponectin expression via different mechanisms in 3 T 3-L 1 adipocytes. Molecular nutrition $\& 3$ food research. 2012;56(12):1783-1793.

55. Zhang H-M, Chen S-W, Zhang L-S, Feng X-F. The effects of soy isoflavone on insulin sensitivity and adipocytokines in insulin resistant rats administered with high-fat diet. Natural product research. 2008;22(18):1637-1649.

\section{Hosted file}

Figure 1.docx available at https://authorea.com/users/355778/articles/478890-the-effect-ofsoy-and-soy-product-supplementation-on-circulating-adiponectin-and-leptin-concentrationa-systematic-review-and-meta-analysis-of-randomized-controlled-trials

\section{Hosted file}

Figure 2.docx available at https://authorea.com/users/355778/articles/478890-the-effect-ofsoy-and-soy-product-supplementation-on-circulating-adiponectin-and-leptin-concentrationa-systematic-review-and-meta-analysis-of-randomized-controlled-trials

\section{Hosted file}

Figure 3.docx available at https://authorea.com/users/355778/articles/478890-the-effect-ofsoy-and-soy-product-supplementation-on-circulating-adiponectin-and-leptin-concentrationa-systematic-review-and-meta-analysis-of-randomized-controlled-trials

\section{Hosted file}

Figure 4.docx available at https://authorea.com/users/355778/articles/478890-the-effect-ofsoy-and-soy-product-supplementation-on-circulating-adiponectin-and-leptin-concentrationa-systematic-review-and-meta-analysis-of-randomized-controlled-trials

\section{Hosted file}

Figure 5.docx available at https://authorea.com/users/355778/articles/478890-the-effect-ofsoy-and-soy-product-supplementation-on-circulating-adiponectin-and-leptin-concentrationa-systematic-review-and-meta-analysis-of-randomized-controlled-trials

\section{Hosted file}

Table 1. Summary of relevant sources of data1.docx available at https://authorea.com/ users/355778/articles/478890-the-effect-of-soy-and-soy-product-supplementation-oncirculating-adiponectin-and-leptin-concentration-a-systematic-review-and-meta-analysisof-randomized-controlled-trials

\section{Hosted file}

Table 2. Cochrane Risk of Bias Assessment1.docx available at https://authorea.com/ users/355778/articles/478890-the-effect-of-soy-and-soy-product-supplementation-oncirculating-adiponectin-and-leptin-concentration-a-systematic-review-and-meta-analysisof-randomized-controlled-trials

\section{Hosted file}

Table 3. subgroup adipokines11.docx available at https://authorea.com/users/355778/articles/ 478890-the-effect-of-soy-and-soy-product-supplementation-on-circulating-adiponectinand-leptin-concentration-a-systematic-review-and-meta-analysis-of-randomized-controlledtrials 